\title{
ARTICLE
}

Translational Therapeutics

\section{Hsp60 and IL-8 axis promotes apoptosis resistance in cancer}

\author{
Sandeep Kumar ${ }^{1,2}$, Jordan O'Malley ${ }^{1}$, Ajay Kumar Chaudhary ${ }^{1}$, Joseph R. Inigo ${ }^{1}$, Neelu Yadav ${ }^{1}$, Rahul Kumar ${ }^{1}$ and Dhyan Chandra ${ }^{1}$
}

BACKGROUND: Interleukin-8 (IL-8) and heat shock protein 60 (Hsp60) play crucial roles in cell survival and maintenance of cellular homoeostasis. However, cross talks between these two proteins are not defined.

METHODS: IL-8 expression in tumour tissue sections was analysed by immunohistochemistry. IL-8 expression and release in cancer cells was quantified using enzyme-linked immunosorbent assay (ELISA). Apoptosis was quantified using caspase activity and Annexin-V/PI staining.

RESULTS: We observed IL-8 release from cancer cells in response to histone deacetylase inhibitor, apicidin (Api), and noncompetitive inhibitor of the sarco/endoplasmic reticulum $\mathrm{Ca}^{2+}$ ATPase, thapsigargin (TG). IL-8 release was increased upon TGtreatment. TG-induced IL-8 expression was reduced in the presence of Api in Bax-dependent manner. Increased apoptosis was associated with decreased IL-8 expression in response to combined treatment of TG and Api. TG and Api combination induced caspase- 8 and caspase-9 dependent apoptosis. Hsp60 knockdown abrogated IL-8 expression induced by Api, TG, and their combination. The level of TGF- $\beta$, an upstream regulator of IL-8, was decreased upon Hsp60-silencing. Knocking down Hsp60 decreased IL-8 expression and its release in prostate cancer cell xenograft tumours in SCID mice.

CONCLUSION: This study describes the underlying mechanism associated with apoptosis resistance mediated via Hsp60-IL-8 axis in cancer.

British Journal of Cancer (2019) 121:934-943; https://doi.org/10.1038/s41416-019-0617-0

\section{BACKGROUND}

Drug resistance in malignant diseases is frequently observed and is an important concern for cancer treatment in the clinics. One of the main contributing factors for drug resistance is the evasion of apoptosis by tumour cells. Resistance to apoptosis is an accumulative outcome of several factors present within tumour microenvironment (TME). Cytokines and chemokines are important components of TME. ${ }^{1}$ Interleukin-8 (IL-8) or CXCL8 (C-X-C motif ligand 8 ) is a member of the chemokine family and associates with angiogenesis and endothelial cell migration. ${ }^{2,3}$ IL-8 participates in various cellular processes in cancer causing increased tumour progression and angiogenesis. Considering the important role of IL-8, it has been suggested as a biomarker to predict recurrence and overall survival of patients with non-smallcell lung cancer. ${ }^{4}$ Indeed, overexpression of $\mathrm{IL}-8$ has been associated with many human tumours, including colorectal cancer (CRC) leading to poor prognosis. ${ }^{5,6}$ Since IL-8 promotes tumour growth, metastasis and angiogenesis, IL- 8 could be an important therapeutic target in CRC. ${ }^{7}$ Overexpression of IL-8 renders colon cancer cells resistant to oxaliplatin while IL-8 silencing sensitises colon cancer cells to oxaliplatin. ${ }^{7}$ IL-8 is produced by activated endothelial cells in varieties of cancer types. ${ }^{8}$ In gastric carcinoma cells, IL-8 expression is associated with growth and vascularity of tumours. ${ }^{9,10}$ In colon cancer, constitutive expression of IL-8 correlates with metastatic potential and development of distant metastases. ${ }^{112}$ Pronounced release of IL-8 and CXC-family chemokines is reported from various types of cancer cell lines including prostate cancer cells. ${ }^{13}$ Transforming growth factor- $\beta$ (TGF- $\beta$ ), a multifunctional cytokine acts upstream of IL-8 and regulates its function in prostate cancer. ${ }^{14}$ However, mechanisms of IL-8 mediated cellular signalling and its implication in cancer cell survival needs further characterisation.

In addition to IL-8, heat shock proteins (Hsps) or stress proteins have also been associated with TME and poor prognosis in various types of cancer. ${ }^{15}$ Heat shock protein 60 (Hsp60) expression levels correlates with cervix and colon carcinogenesis. ${ }^{16,17} \mathrm{Hsp60}$ is a key chaperonin, plays an essential role in the transport and folding of mitochondrial proteins, and is increased in different types of cancer. Hsp60 is overexpressed in prostate tumours and is strongly associated with prognostic clinical parameters. ${ }^{18} \mathrm{Hsp} 60$ expression in prostate cancer was correlated with biochemical recurrence. ${ }^{19}$ Similarly, Hsp60 expression associates with tumour differentiation and stages in colorectal cancer. ${ }^{20}$ Exposure to extracellular Hsp60 renders the human lymphoma cell line U937 resistant to oxidative damage-induced apoptosis. ${ }^{21}$ Hsp60 also restrains p53 function by stabilising the antiapoptotic protein survivin, thus promoting cell proliferation. ${ }^{22}$ These findings provide strong relevance that the overexpression of IL-8 and Hsp60 could play critical role in maintaining TME, growth and invasion of cancer cells. Thus, we propose that inhibition of IL-8 and $\mathrm{Hsp} 60$ axis may attenuate cancer cell growth and survival.

For the first time, we report that Hsp60 regulates IL-8 production and release both in vitro cell culture and in vivo tumour xenografts models. We observed that thapsigargin (TG), a

${ }^{1}$ Department of Pharmacology and Therapeutics, Roswell Park Comprehensive Cancer Center, Buffalo, NY, USA

Correspondence: Dhyan Chandra (dhyan.chandra@roswellpark.org)

${ }^{2}$ Present address: Department of Surgery, Division of Surgical Oncology, University of Illinois at Chicago, Chicago, IL 60612, USA

Received: 26 July 2019 Revised: 21 September 2019 Accepted: 8 October 2019

Published online: 1 November 2019 
non-competitive inhibitor of the sarco/endoplasmic reticulum $\mathrm{Ca}^{2+}$ ATPase, induced robust expression of IL-8, which can be associated with IL-8 mediated cancer cell survival. A nanomolar combination of TG with histone deacetylase inhibitor apicidin (Api) downregulated IL-8 expression and induced apoptosis in colon and prostate cancer cells. Knockdown of caspase- 8 and caspase-9 significantly decreased effector caspase-3 activity induced by combined treatment of TG and Api. Interestingly, reconstitution of Bax in cancer cells decreased IL-8 levels and knockout of Bax in cancer cells upregulated IL-8 expression and its release. IL-8 release was drastically reduced upon $\mathrm{Hsp} 60$ knockdown. The PC-3 prostate cancer cell xenograft study utilising Hsp60-knockdown and mock PC-3 cells in SCID mice demonstrated down-regulation of $\mathrm{IL}-8$ in serum in Hsp60 knockdown xenografts. Collectively, our results provide a novel insight on IL-8 regulation by Hsp60 in cancer cells.

\section{MATERIALS AND METHODS}

Cell lines and reagents

Cell lines HCT116 wild type (WT) and HCT116 $\mathrm{Bax}^{-/-}$, androgendependent $\mathrm{LNCaP}$ cells and androgen-independent cell lines (DU145 Mock, DU145 Bax reconstituted and PC-3 cells) were either provided by Drs B. Vogelstein and Peter Daniel or purchased from American type culture collection. ${ }^{23,24}$ All cells were cultured using their respective medium and maintained at $37{ }^{\circ} \mathrm{C}$ in a humidified atmosphere in the presence of $5 \% \mathrm{CO}_{2}$. Antibodies and sources are: IL-8 (Santa Cruz Biotechnology, Inc. Dallas, TX, USA, Cat \# sc8427); Caspase-8 (Enzo Life Sciences, Inc., Farmingdale, NY, USA, Cat \# ALX-804-242-C100); Caspase-9 (Cell Signaling Technology, Danvers, MA, USA, Cat \# 9502), beta actin (Santa Cruz Biotechnology, Inc., Cat \# sc-47778 HRP) and Hsp60 (MilliporeSigma, Burlington, MA, USA, Cat \# MAB3514). All reagents used in this study were of highest grade of purity.

Treatment

Apicidin (Api) and Thapsigargin (TG) were purchased from Enzo Life Sciences, Inc. All cell lines were treated with either $200 \mathrm{nM}$ Api or $500 \mathrm{nM}$ TG alone or in combination. Cells $\left(2.0 \times 10^{5}\right.$ cells $\left./ \mathrm{ml}\right)$ were seeded on to six-well cell culture plate for $24 \mathrm{~h}$ and treated with different drugs alone or in combination.

\section{TCGA analysis}

The TCGA colon adenocarcinoma (COAD) and colorectal adenocarcinoma (COREAD) datasets (version 2016-08-16) were retrieved from the UCSC Xena Browser. The polyA+ IlluminaHiSeq gene expression dataset was downloaded in its normalised format. RNA-seq values were grouped between primary tumour (PT) and matched non-tumour (MN) samples. The average transcript reads were calculated for each group. The RPKM method was used to quantify gene expression from RNA sequencing data by normalising for total read length and the number of sequencing reads. A student's $t$-test was performed between matched normal and primary tumour groups.

Isolation of whole cell lysate

These processes were carried out according to the protocol described earlier. ${ }^{25}$

\section{Western blotting}

Whole-cell lysate (WCL) was prepared using NP-40-HEPES lysis buffer. WCL was separated by precast 26 well, 4-20\% sodium dodecyl sulfate-polyacrylamide gel electrophoresis (SDS-PAGE) procured from Bio-Rad (Hercules, CA, USA) and transferred on to nitrocellulose membrane (Bio-Rad, Hercules, CA). Membranes were blocked in $5 \%$ non-fat milk for $30 \mathrm{~min}$ and washed with PBS-T (1X PBS and $0.1 \%$ Tween 20) and further incubated with respective primary antibody. Anti-mouse or anti-rabbit horseradish peroxidase-conjugated antibodies (Amersham Pharmacia Biotech, Piscataway, NJ, USA) were used as secondary antibody. After washing with PBS-T, proteins were detected using Clarity chemiluminescent reagent (Bio-Rad) and X-Ray films (ASI, Fort Lauderdale, FL, USA). Membranes were stripped using stripping buffer and probed with HRP conjugated beta-actin antibody.

Caspase-8, caspase-9, Hsp60 and IL-8 knockdown using lentiviral shRNAs

Lentiviral shRNAs were procured from the Gene Modulation Services Resource (GMSR) core of Roswell Park Comprehensive Cancer Center, for knocking down expression of various genes in cancer cells. The shRNA sequences were: caspase-8 (5'-GACTT CAGCAGAAATCTT- $3^{\prime}$ ), caspase- 9 (5'-CCAGGCAGCTGATCATA GA-3'), Hsp60 or HSPD1 (5'-GCTATATTTCTCCATACTTTA-3'), and CXCL8 or IL-8 (5'-TGCTATTTGTATATTCTCC- $\left.3^{\prime}\right)$. Briefly, cells were seeded $\left(5 \times 10^{4}\right.$ cells) per well of 6 -well plates. After $24 \mathrm{~h}$, polybrene $(8 \mu \mathrm{g} / \mathrm{ml})$ was added to the media. After $1 \mathrm{~h}$, mock shRNA or gene specific shRNA (caspase-8, caspase-9, IL-8 and Hsp60) lentiviral particles were added at MOI of 3 . After $48 \mathrm{~h}$ of transduction, media was replaced with fresh media containing 1 $\mu \mathrm{g} / \mathrm{ml}$ puromycin for selection of transduced cells. Knockdown of targeted gene was confirmed using immunoblotting or ELISA.

Bright field microscopy

Cellular morphological changes induced by treatment as well as in untreated control were assessed by bright field microscopy. Images were captured without refreshing medium by an inverted microscope (Olympus, Waltham, MA, USA).

\section{ELISA assay}

Estimation of IL-8 and TGF- $\beta 1$ levels was carried out using commercially available kits (eBiosciences, San Diego, CA, USA, and Ray Biotech, Peachtree Corners, GA, USA respectively). For data normalisation, the value of cytokines in lysates or supernatant was divided by protein concentration of lysates.

\section{Caspase-3 activities}

Caspase- 3 activity was quantified using a fluorometric method described earlier. ${ }^{26}$ In a 96-well plate, cell lysates prepared in NP40-HEPES lysis buffer were incubated with DEVD-AFC (caspase3 substrate) at $37^{\circ} \mathrm{C}$ for $90 \mathrm{~min}$ in caspase activity assay buffer (50 $\mathrm{mM}$ HEPES pH 7.4, $150 \mathrm{mM} \mathrm{NaCl}, 0.5 \%$ CHAPS, $1 \mathrm{mM}$ EDTA, $1 \mathrm{mM}$ DTT, $25 \%$ glycerol). Fluorescence intensity was detected using a Synergy microplate reader at excitation and emission wavelengths of $400 \mathrm{~nm}$ and $508 \mathrm{~nm}$, respectively. Arbitrary fluorescence units were normalised with protein content of cell lysates and represented as fold change compared to control groups. Protein concentration of WCL was determined by microBCA kit (Thermo Fisher Scientific, Grand Island, NY, USA) where bovine serum albumin (BSA) was taken as a standard. The fluorescence obtained for caspase-3 was normalised by their respective protein concentration. The results were presented in the fold change when compared to control.

Annexin/PI staining

Cells were treated with various anticancer agents or with vehicle for various time periods followed by staining with annexin-V-Alexa flour 488/PI kit (Invitrogen, Waltham, MA, USA) according to the manufacturer's instructions. The stained cells were analysed by flow cytometry (LSRIIA, BD Biosciences, San Jose, CA, USA) collecting 10000 events. Data were analysed using Win List 3D 7.1 software.

Mice and PC-3 xenograft study

Male SCID (C.B-Igh- 1 b/lcrTac-Prkdc ${ }^{\text {scid }}$ ) mice (6-weeks-old; $\sim 25 \mathrm{~g}$ body weight) were purchased from an in-house breeding colony maintained by Roswell Park Comprehensive Cancer Center 
a

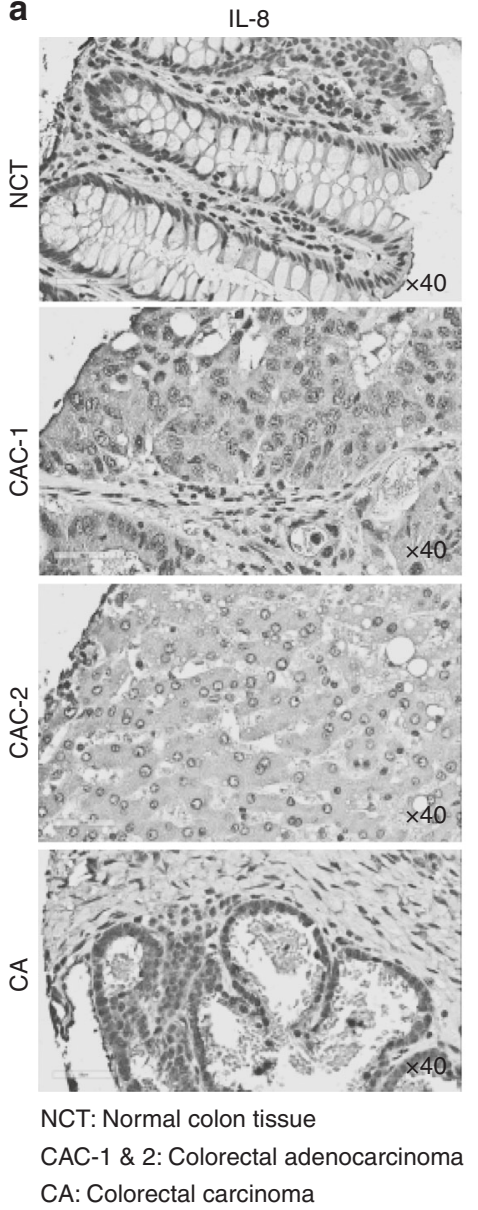

b
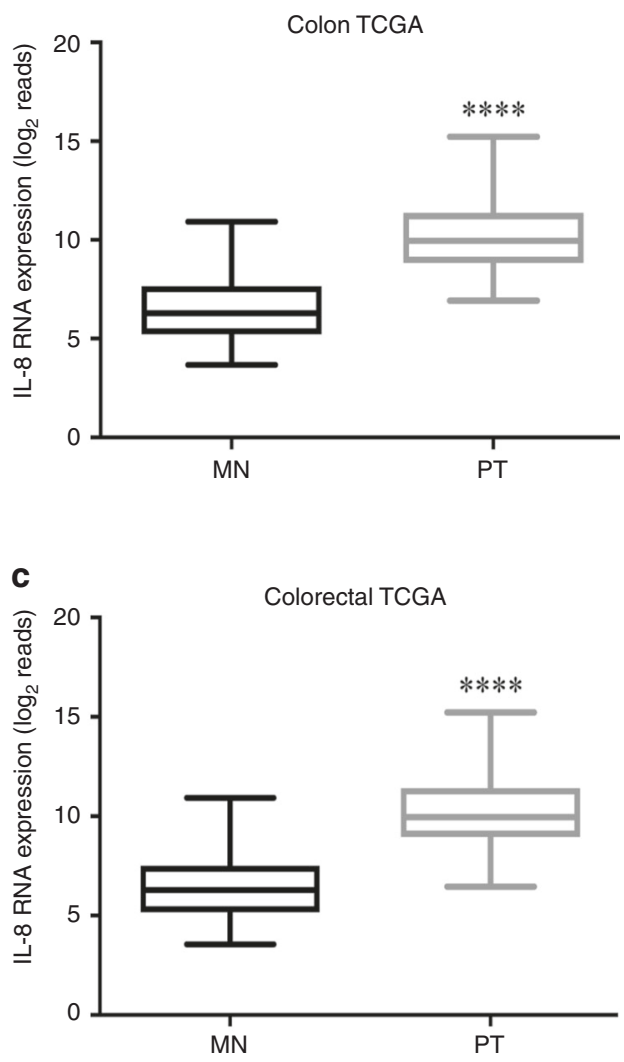

Fig. 1 IL-8 is overexpressed in colon cancers. a Immunohistochemistry (IHC) analysis of IL-8 expression in normal colon, human colorectal adenocarcinoma, and colorectal carcinoma tissue samples using tissue microarray (TMA) sections. Images were scanned using Aperio ImageScope. b, c TCGA analysis for IL-8 transcript levels in colon $(n=26)$ and colorectal cancer $(n=34)$. MN matched non-tumour tissues, PT primary tumour tissues. Data is presented as mean \pm SD. ${ }^{* * *} p<0.05$ vs respective controls

Laboratory Animal Shared Resource. Mice were housed in standard ventilated cages, up to five animals per cage, with commercially available laboratory animal cages bedding at $24 \pm 1^{\circ} \mathrm{C}$ in a lightcontrolled room (light: 6:00-18:00 h, dark: 18:00-6:00 h) and a relative humidity of $55 \% \pm 5 \%$. Mice were given an ad libitum supply of filtered pathogen-free air, food, and water. Mice were acclimatised for a week and prior to implantation of tumours during evening hours. Animals were anaesthetised by inhalation of isoflurane mixed with oxygen using an isoflurane vaporiser. Mock or Hsp60 knockdown PC-3 cells $\left(1 \times 10^{6}\right.$ cells) were resuspended in ice cold PBS and mixed with matrigel (50:50 v/v) and injected subcutaneously in both flanks of SCID mice (five mice/ group) under anaesthesia using $27 \mathrm{G}$ needle inside a biosafety cabinet. Isoflurane inhalation anaesthesia was chosen because of its faster induction and recovery, minimal effect on cardiovascular function and negligible metabolism. Animals were monitored daily after implantation of tumour. Tumours size in animals were measured twice weekly using callipers. Body weight of animals were measured twice a week. Once mock PC-3 xenografts reached $2 \mathrm{~cm}$ in cumulative diameter, mice were killed by carbon dioxide inhalation followed by cardiac puncture for exsanguination of blood for serum and serum kept at $-80^{\circ} \mathrm{C}$ until further use. Tumours were harvested, cut into small pieces and fixed in $10 \%$ formalin (at least for $48 \mathrm{~h}$ ) followed by $70 \%$ ethanol for a week. After fixation, tumours were placed into cassettes for processing and embedding in paraffin blocks. For immunohistochemistry, paraffin-embedded tumour tissues were sectioned (3-5 $\mu \mathrm{m})$ and stained with haematoxylin and eosin (H\&E). To determine IL-8 expression in xenograft tissues, we performed immunohistochemistry and viewed under a microscope (Olympus, Waltham, MA, USA). Serum IL-8 levels were determined by human IL-8 specific ELISA.

Immunohistochemistry

For tissue section staining, following de-paraffinisation and dehydration, slides were incubated in 3\% hydrogen peroxide to block endogenous peroxidase activity. For antigen retrieval, slides were incubated in $10 \mathrm{mM}$ citrate buffer, $\mathrm{pH}$ 6.0, for $15 \mathrm{~min}$ in a microwave oven. Then slides were sequentially incubated in blocking solution ( $10 \%$ goat serum in $\mathrm{PBS}, 30 \mathrm{~min}$ ), primary antibody (anti-IL-8; 1:1,000 for overnight at $4{ }^{\circ} \mathrm{C}$ ), and secondary antibody (goat anti-rabbit lgG conjugated to HRP; 1:4,000 for $1 \mathrm{~h}$ at RT). Slides were developed with DAB peroxidase substrate kit (Vector Labs, Burlingame, CA, USA).

\section{Statistical analysis}

Significant differences between means of presented data including studies related to PC-3 cell xenografts were assessed using two groups Student's t-test and multiple groups Bonferroni multiple comparison test by Graph Pad Prism 5.0. Significance was denoted as compared to control, unless otherwise indicated. 
a
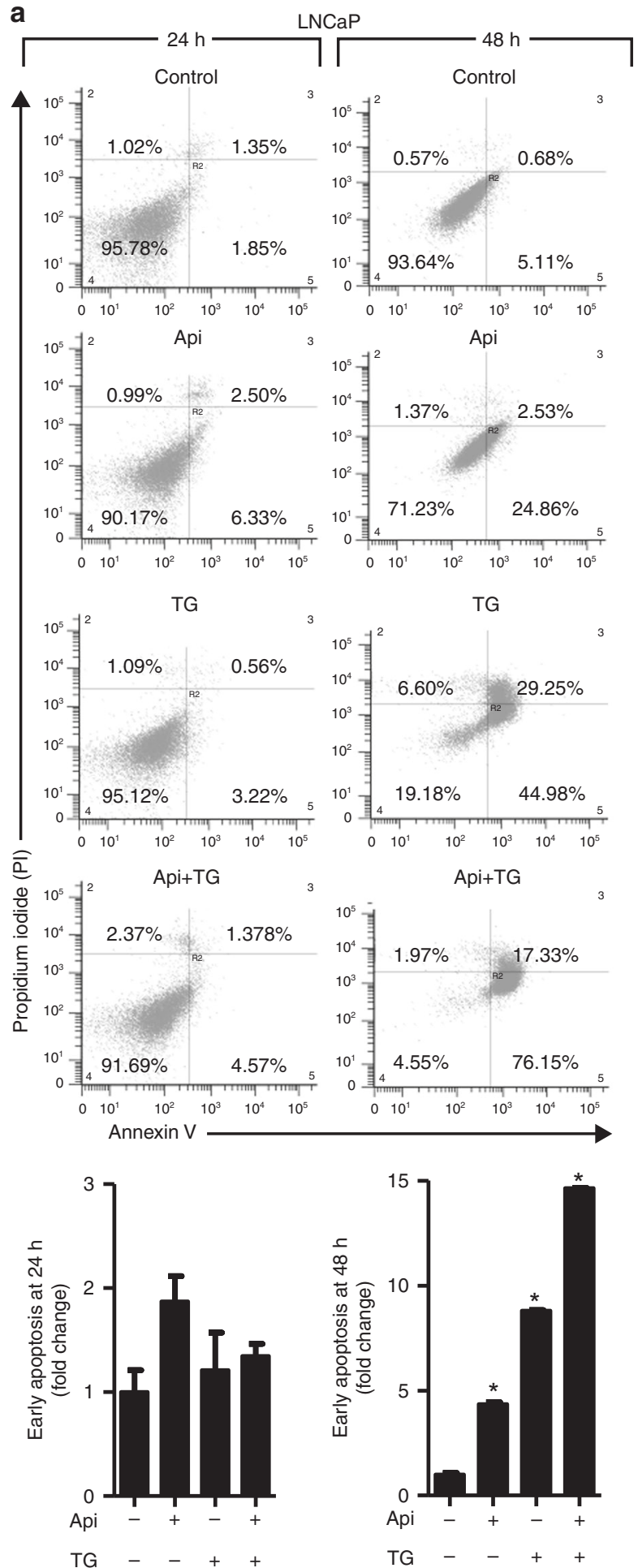

b
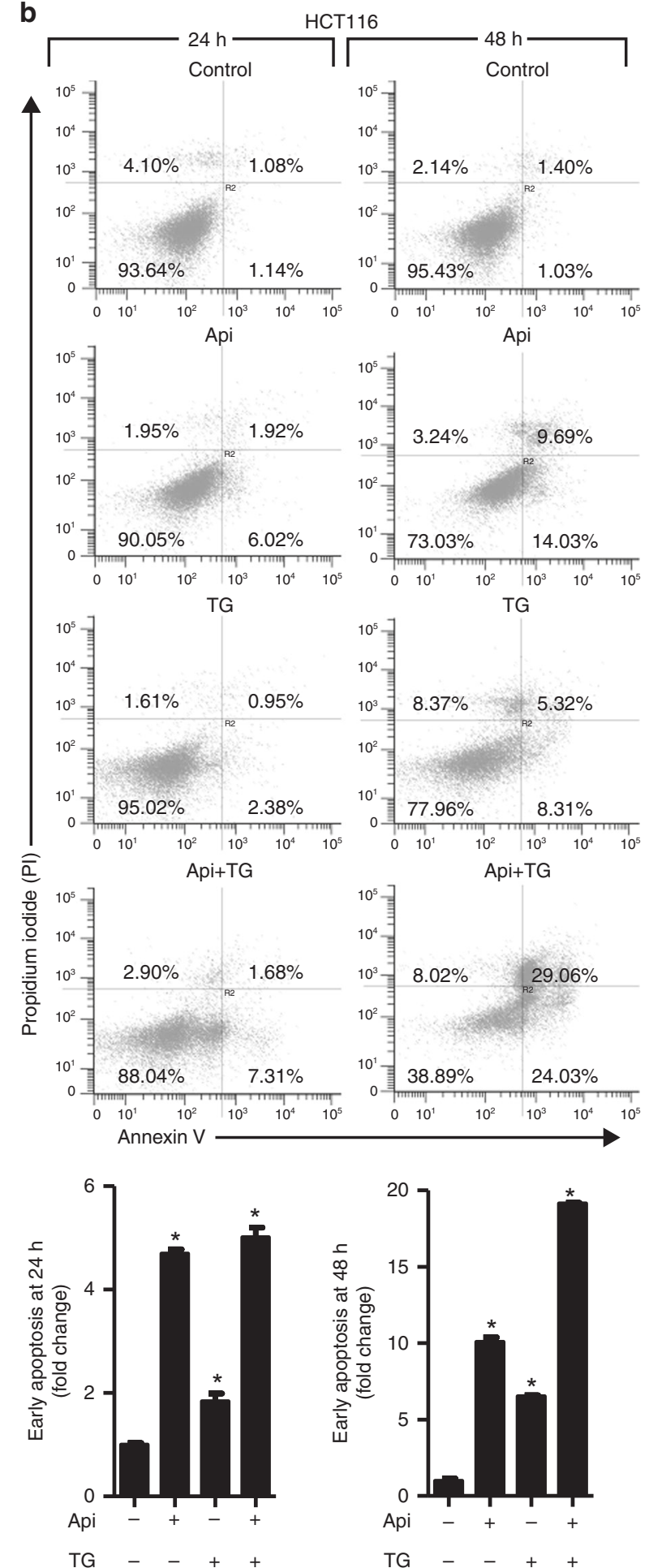

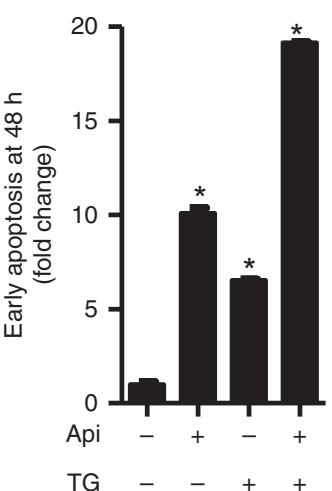

Fig. 2 Combination of Api and TG induces apoptosis. a, b Flow cytometry analysis of apoptosis in LNCaP and HCT-116 cells using Annexin-V and PI staining. A total 10,000 events were captured, and result was analysed by Win List software. Data are mean \pm SD $(n=3)$. ${ }^{*} p<0.05$ vs respective controls

\section{RESULTS}

IL-8 is overexpressed in colorectal cancers

The chemokine, IL-8 plays an important role in tumour growth, angiogenesis, and metastasis. ${ }^{27,28}$ To understand the expression level of IL-8 in human cancer, we used tumour microarray (TMA) of multiple cancers and performed immunohistochemistry (IHC) staining. The multi-cancer TMA showed increased expression of IL-8 in various cancers including colorectal adenocarcinoma (CAC1 and (AC-2), and colorectal carcinoma compared to normal colon tissue (Fig. 1a). We further estimated IL-8 mRNA expression in TCGA-colon and TCGA-colorectal cancer database and observed overexpression of IL-8 levels in both cancer types compared to 


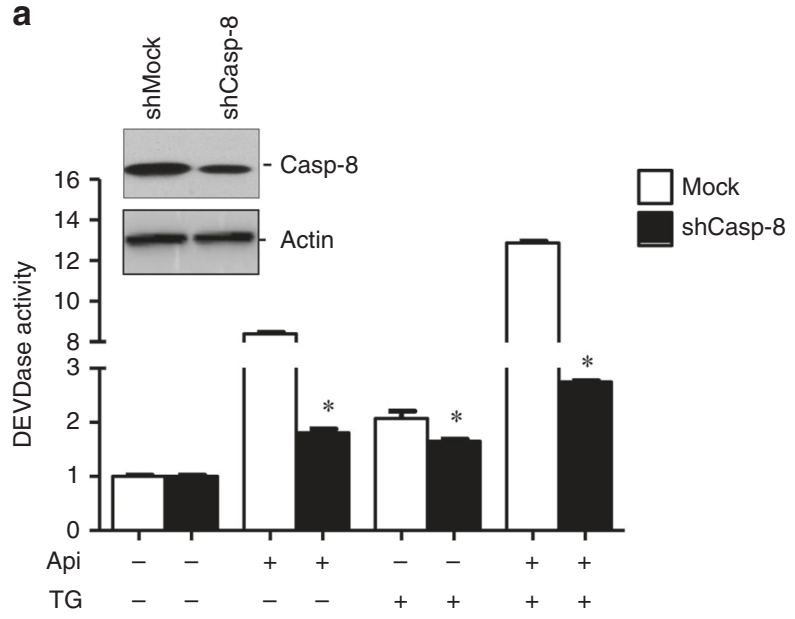

b

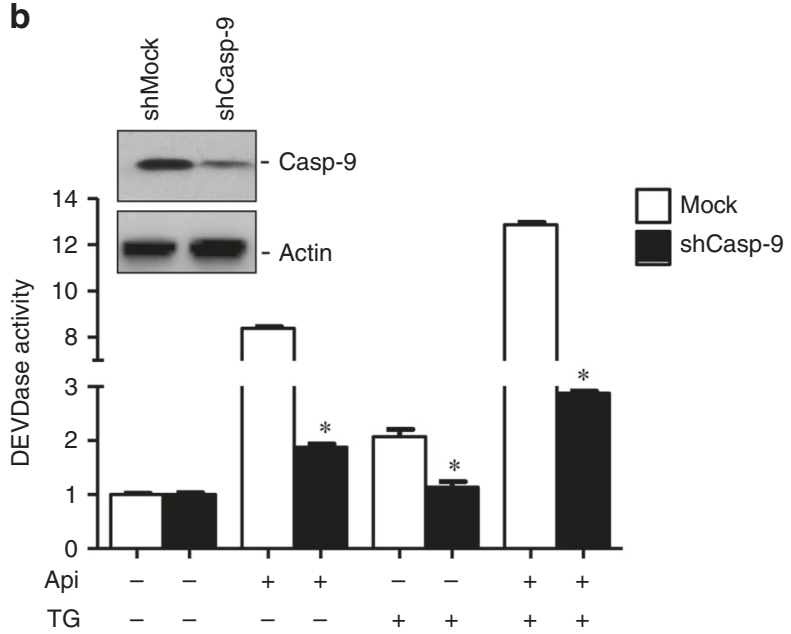

Fig. 3 Combination of Api and TG induces caspase activity. Caspase8 (Casp-8) and caspase-9 (Casp-9) were silenced in HCT116 cells using shRNA. Mock shRNA was used as control. a, b Caspase-3 activities were measured in mock and caspase- 8 and caspase- 9 silenced cells following treatment with Api or TG alone or their combination. Whole cell lysates were used to analyse caspase- 8 and caspase-9 knockdown using western blotting. Actin serves as a loading control. Data are mean \pm SD $(n=3)$. ${ }^{*} p<0.05$ vs respective controls/groups

matched non-tumour specimens (Fig. 1b, c). Together, IHC and TCGA database analysis suggests that IL-8 is overexpressed in colorectal cancer.

Combination of Api and TG enhances apoptosis and reduces IL-8 expression in cancer cells

Since we observed that IL-8 is overexpressed in cancer, we next determined whether/how IL-8 is involved in apoptosis resistance in colon and prostate cancer cells. Thus, we selected two pharmacological inhibitors, Api and TG, which are known to induce autocrine release of IL-8 from cells. ${ }^{29,30}$ Drug-induced IL8 signalling promotes resistance to apoptosis in LNCaP and PC-3 prostate cancer cells. ${ }^{31}$ To determine the importance of IL-8 release on apoptosis, we treated cancer cells with Api and TG alone or in a combination. Annexin/PI staining suggests increased cell death in a time-dependent manner induced by Api and TG in prostate and colon cancer cells (Fig. 2a, b). We have used very low doses of Api, or TG as compared to earlier studies ${ }^{32-34}$ in concluding that this combination does not show overt toxicity.
Anticancer activities in response to the exposure of these drugs were more effective at later time points $(48 \mathrm{~h})$ in both cancer cell types. Apoptosis is mediated by several factors including activation of caspases. ${ }^{25,35}$ Caspases are involved in apoptosis and have been sub classified by their mechanism of action as initiator caspases such as caspase- 8 and -9 or executioner caspases such as caspase-3, -6 , and $-7 . .^{36}$ To determine whether IL-8 mediated apoptosis requires caspases, we treated mock, caspase- 8 and caspase- 9 knockdown HCT116 colon cancer cells with TG and Api alone or their combination. We observed that combination treatment of Api and TG significantly induced caspase- 3 activity in mock HCT116 cells (Fig. 3a, b). Caspase-8 and caspase-9 knockdown in HCT116 cells inhibited caspase-3 activity confirming the involvement of both of the initiator caspases in Api and TG combination treatment-induced apoptotic cell death in cancer cells (Fig. 3a, b). Since Api and TG are known to induce IL-8, we determined expression of IL-8 upon treatment of TG and Api alone or in a combination in cancer cells. We observed that treatment of TG induces robust IL-8 production and release whereas Api-induced IL-8 level and release was not as prominent as TG (Fig. 4a, b). Interestingly, combination of Api with TG abrogates IL-8 production and release induced by TG. Taken together, our results suggest that increased autocrine release of IL-8 is associated with decreased caspase activation and apoptosis.

Bax downregulates IL-8 expression and release

Pro-apoptotic protein Bax plays a critical role in the permeabilisation of outer mitochondrial membrane leading to cytochrome c release, caspase activation and apoptosis. ${ }^{37}$ To address the importance of Bax in IL-8 mediated apoptosis, we used isogenic colon cancer cell lines HCT116 wild type (WT) and $\mathrm{Bax}^{-1-}$ as well as isogenic prostate cancer cell line DU145 mock and Bax reconstituted (DU145 $\mathrm{Bax}^{+/+}$) cells. We observed that Bax reconstitution induced a higher level of cell death in response to Api and TG combination (Fig. 4c). It has been reported that endothelial cells incubated with IL-8 promotes higher levels of BCl2:Bax ratios, ${ }^{2}$ and therefore, we determined interrelation of Bax and IL-8 in prostate and colon cancer cells. We observed that IL-8 expression was significantly decreased upon reconstitution of Bax (Fig. 4d). We further studied the effect of Bax knockout on IL-8 expression in WT and Bax ${ }^{-1-}$ HCT116 cells. IL-8 expression was increased in the absence of Bax (Fig. 4e) in response to combined exposure of TG and Api. Collectively, Bax and IL-8 expression are inversely regulated in prostate and colon cancer cells.

Hsp60 knockdown inhibits TGF- $\beta$ expression, an upstream regulator of IL-8

Acute ablation of Hsp60 destabilises mitochondrial functions leading to increased expression of proapoptotic Bax and Baxdependent apoptosis.22 Since IL-8 and Hsp60 inversely associate with Bax, we next determined effect of Hsp60 knockdown on IL-8 expression. A robust decrease in IL-8 expression was observed upon $\mathrm{Hsp60}$-silencing in LNCaP prostate cancer cells (Fig. 5a). TGF$\beta$ plays a central role in tumour management and regulates expressions of cytokines including IL-8. ${ }^{14}$ We determined the effect of $I L-8$ knockdown on TGF- $\beta$ expression and observed that IL-8 knockdown promotes TGF- $\beta$ expression (Fig. 5b, c). Since Hsp60 promotes IL-8 expression and TGF- $\beta$ also regulates IL-8 levels, we next asked the question, whether Hsp60 is critical for TGF- $\beta$ expression. We used mock and Hsp60 knockdown LNCaP prostate cancer cells and treated with Api or TG alone or in combination. Decreased expression of TGF- $\beta$ in TG alone or in combination of Api and TG was observed in control (mock) LNCaP cells, whereas TGF- $\beta$ was not detectable in Hsp60 knocked down LNCaP cells (Fig. 5d). Taken together, Hsp60 regulates IL-8 expression as well as its upstream regulator TGF- $\beta$ in cancer cells. 
a

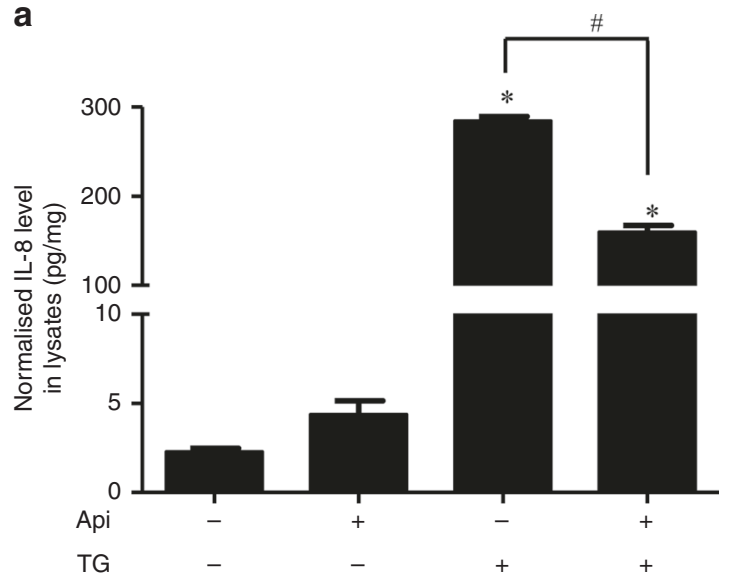

C
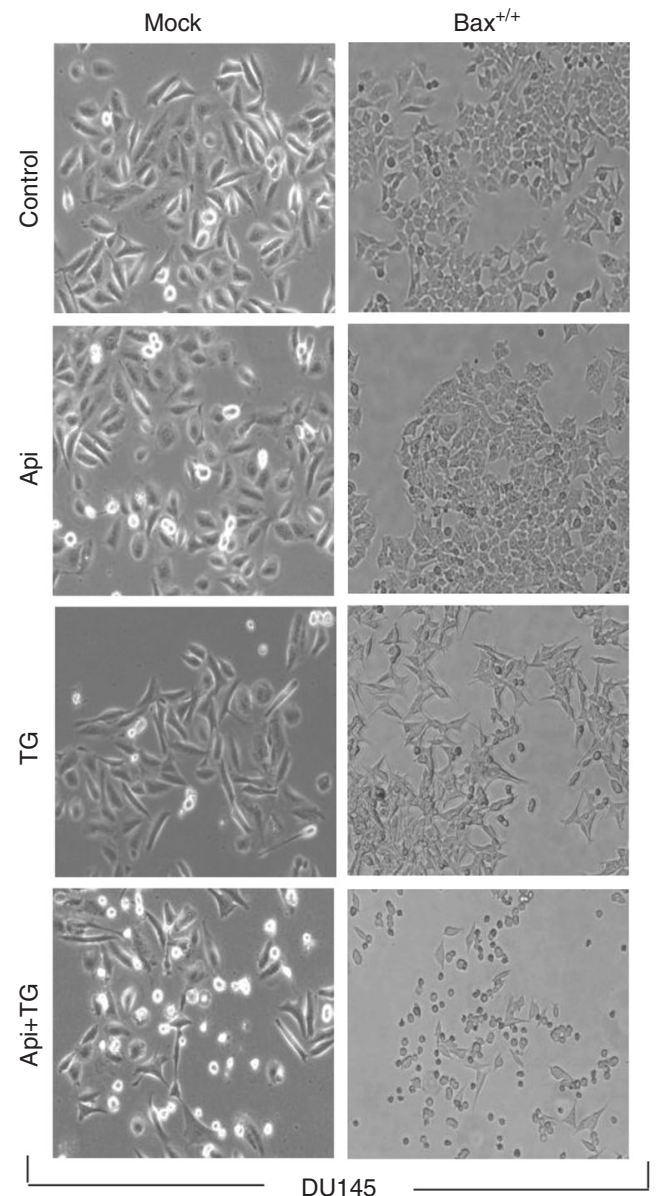

b

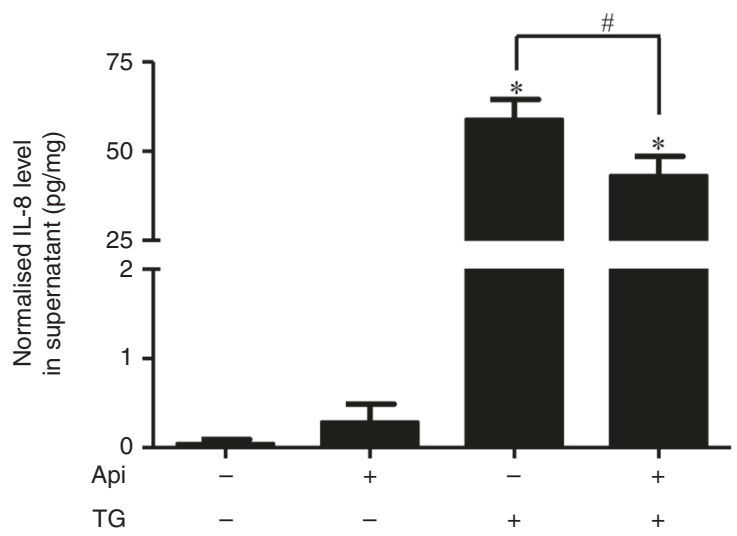

d

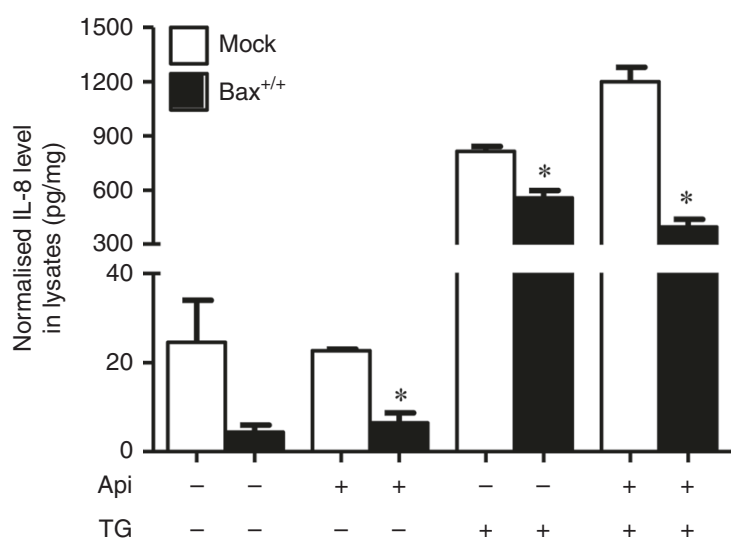

e

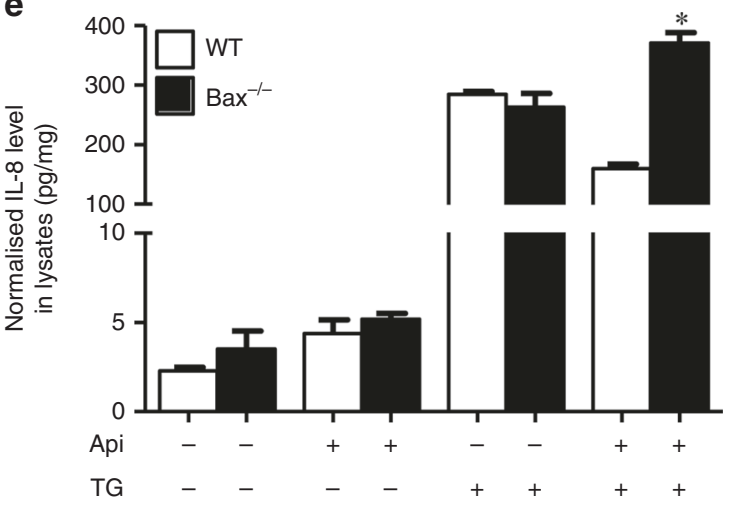

Fig. 4 Bax and IL-8 are inversely correlated in prostate and colon cancer cells. HCT116 cells were treated with Api and TG alone and in combination. The level of IL-8 was determined in lysate (a) and supernatant (b) using ELISA. Mock and Bax reconstituted DU145 cells were treated with Api and TG alone and in combination. (c) Bright field microscopy images of control, Api, TG and Api plus TG treated mock and Bax reconstituted DU145 cells. d IL-8 was quantified by ELISA using DU145 whole cell lysates. e IL-8 was quantified using whole cell lysates isolated from HCT116 WT and Bax knockout cells. Data are mean \pm SD $(n=3) .{ }^{*} p<0.05$ vs respective controls

Hsp60 knockdown inhibits IL-8 expression and release in vivo The overexpression of $\mathrm{Hsp} 60$ associates with increased expression of anti-apoptotic proteins $\mathrm{BCl}-\mathrm{xl}$ and $\mathrm{Bcl}-2$, and decreased expression of the pro-apoptotic protein, Bax. ${ }^{38}$ To understand the physiological relevance of our study, we next performed in vivo experiments to determine whether Hsp60 regulates IL-8 production and release in tumour cells in vivo. We subcutaneously grafted mock and Hsp60 knockdown PC-3 prostate cancer cells in
SCID mice. Human IL-8 levels in mouse serum of mock and Hsp60 knockdown groups were subsequently estimated by human IL-8 specific ELISA. The levels of IL-8 in mouse serum were significantly decreased in Hsp60 knockdown group compared to mock group (Fig. 6a). In the mock group $(n=5)$, levels of IL-8 in serum were 108.5, 83.0, 107.3, 52.0 and $52.0 \mathrm{pg} / \mathrm{ml}$, respectively while in $H$ sp60 knockdown group $(n=5)$, IL-8 levels were 1.01, 5.15, 19.25, 18.55 and $31.24 \mathrm{pg} / \mathrm{ml}$, respectively (Fig. 6a). We also determined IL-8 

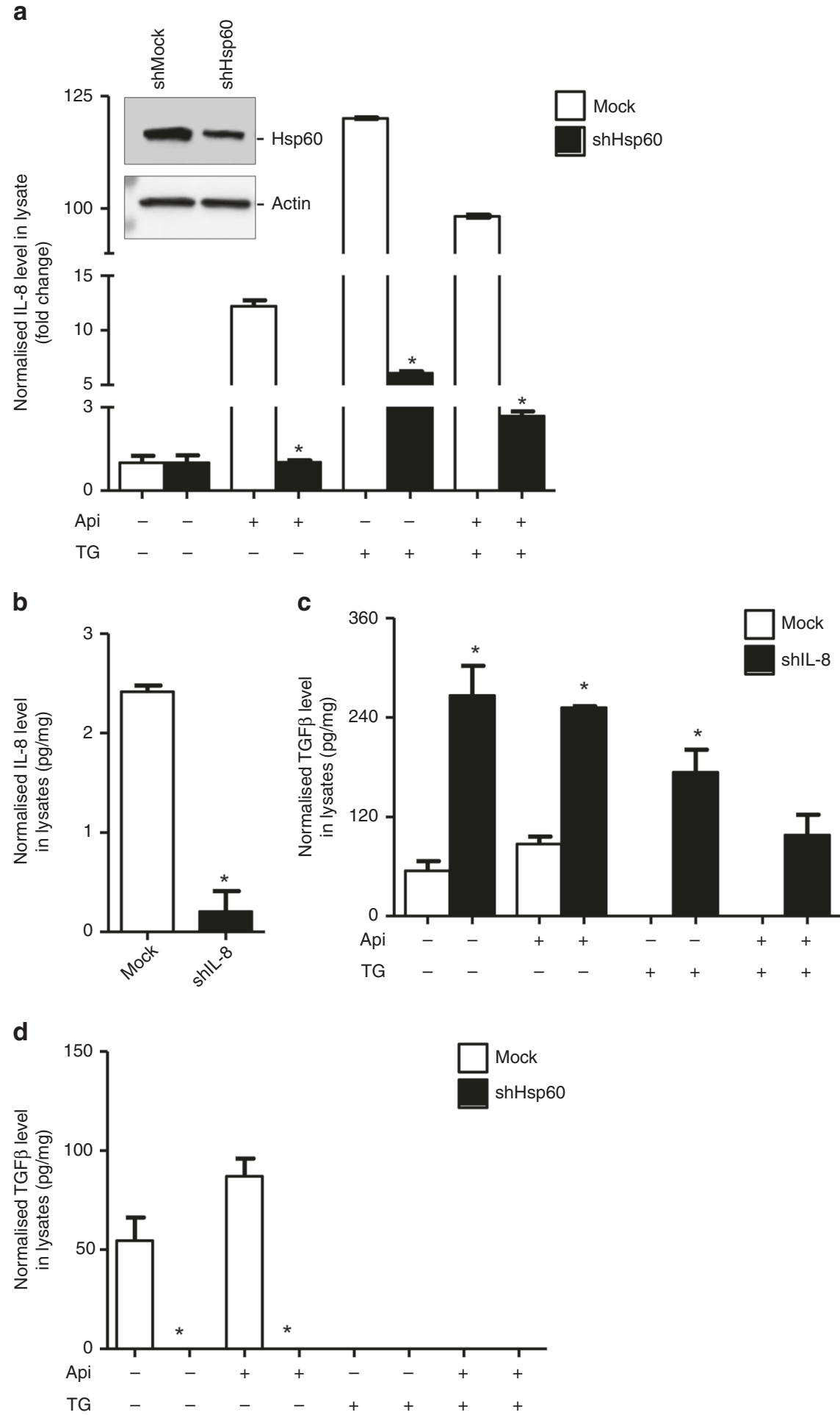

Fig. 5 Hsp60 knockdown inhibits TGF- $\beta$ and IL-8 expression, whereas IL-8 enhances TGF- $\beta$. Hsp60-silenced and mock shRNA LNCaP cells were treated with Api, TG alone or in combination followed by IL-8 quantification using ELISA (a). Whole cell lysates were used to analyse Hsp60 knockdown using Western blotting. Actin serves as a loading control. b IL-8 knockdown was confirmed by ELISA in cell lysate. c Estimation of TGF- $\beta$ in cell lysates using ELISA in mock and IL-8 knockdown LNCaP cells following treatment with Api or TG alone or their combination. d Estimation of TGF- $\beta$ in cell lysates using ELISA in mock and Hsp60 knockdown LNCaP cells following treatment with Api or TG alone or their combination. Data are mean \pm SD $(n=3)$. ${ }^{*} p<0.05$ vs respective controls/groups

expression in tumours by IHC staining using human anti-IL-8 antibody. Concurrent with serum IL-8 results, expression of IL-8 was drastically downregulated in $\mathrm{Hsp} 60$ knock down tumours (Fig. 6b). Taken together, these findings clearly indicate that Hsp60 regulates the IL-8 expression and its release in tumour cells.

\section{DISCUSSION}

Deregulated cytokine expression and signalling play a crucial role in developing drug resistance in cancer. ${ }^{39}$ Aberrant cytokine signalling induces proliferation of tumour cells and facilitates formation of stromal blood vessel networks, which promotes 
b

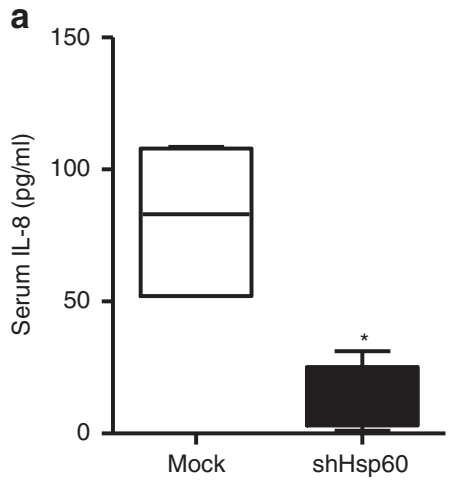

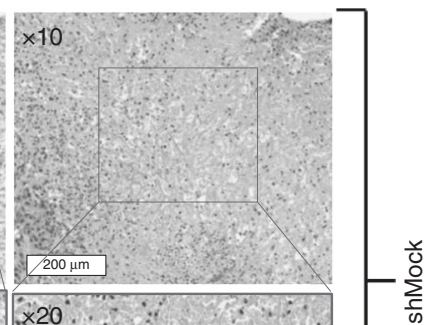
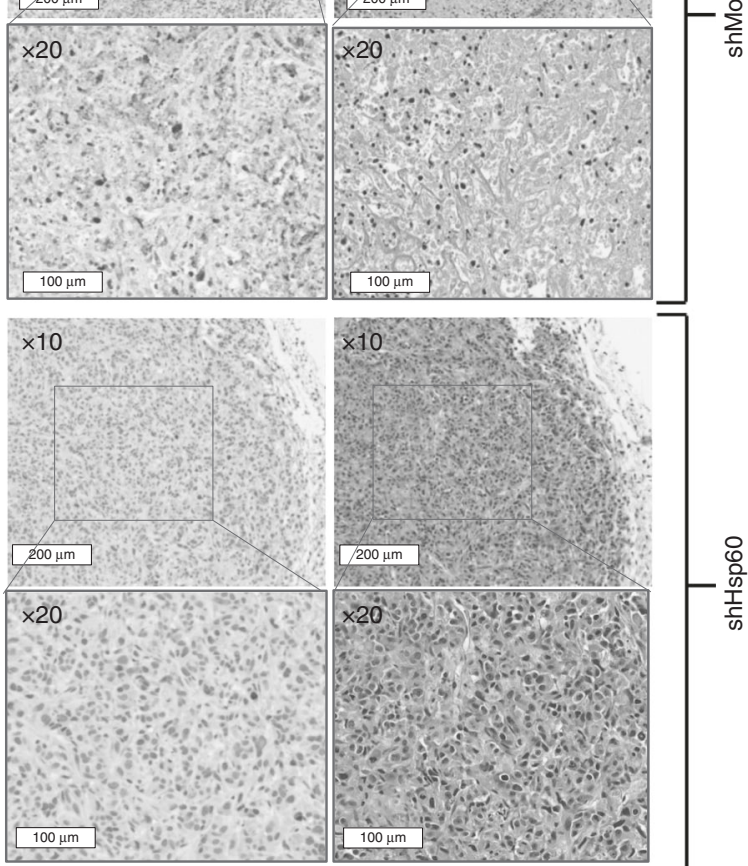

IL-8

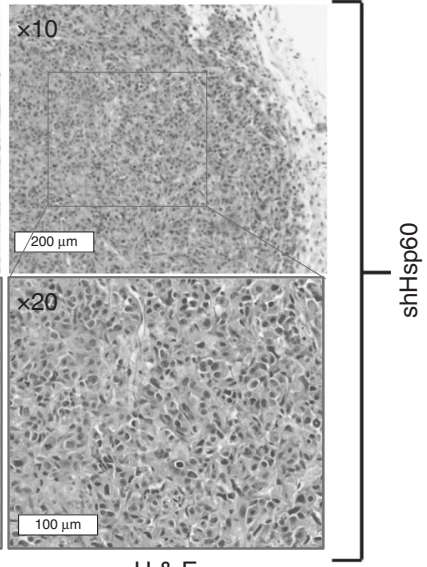

$H \& E$

C

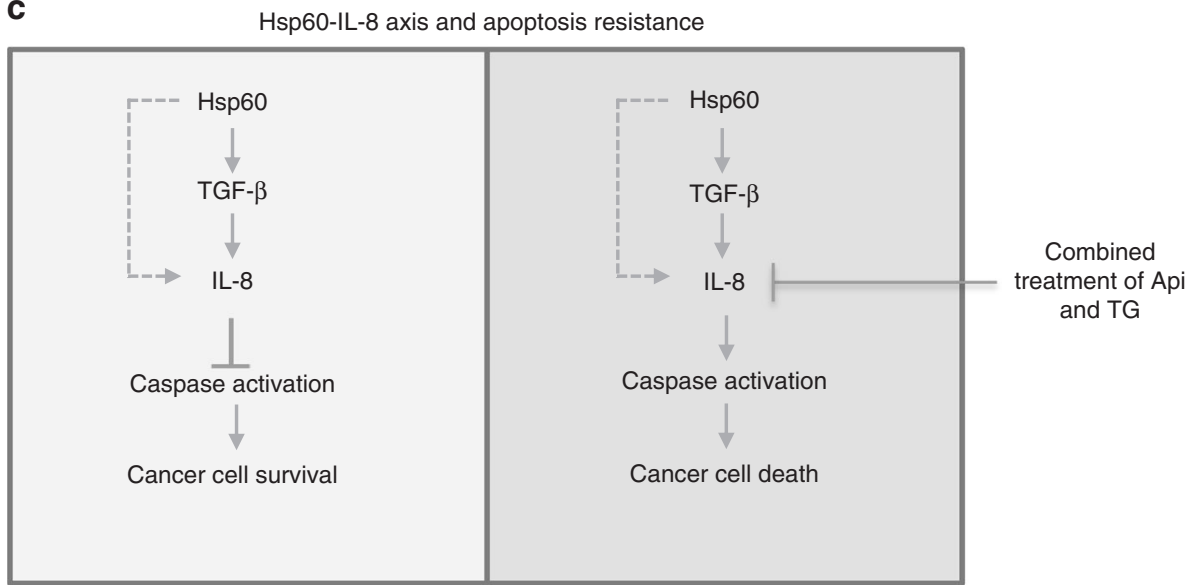

Fig. 6 Hsp60 knockdown inhibits IL-8 expression and release. a Estimation of IL-8 in serum of mock and Hsp60 knockdown PC-3 cell xenografts using ELISA. b Immunohistochemistry of IL-8 in tumour sections of mock and Hsp60 knock down xenografts. c Schematic diagram of Hsp60-IL8 axis and its role in apoptosis resistance. Data are mean \pm SD $(n=5) .{ }^{*} p<0.05$ vs controls

tumour progression and growth. ${ }^{39,40}$ We report that Hsp60 regulates IL-8 expression and release in colon and prostate cancer. Increased levels of IL-8 and Hsp60 are associated with enhanced resistance to apoptosis in cancer cells. Hsp60 either directly or via TGF- $\beta$ upregulates IL-8 expression, which inhibits apoptosis leading to cancer cell survival. The combined treatment of Api and TG downregulates IL-8 expression causing increased caspase activation and cancer cell death (Fig. 6c).

Most of the chemotherapeutic drugs fail to induce efficient apoptosis in cancer cells. Our study provides the underlying mechanism on how autocrine release of IL-8 contributes to tumour growth and apoptosis resistance in cancer cells. Since, Api and TG are reported to induce autocrine release of IL- $8,{ }^{29,30}$ we used these two drugs alone or in combination to study the effect of IL-8 release on apoptosis in prostate and colon cancer cells. Drug-induced IL-8 upregulation has also been reported in dacarbazine treated melanoma cells, etoposide and mitomycin C treated human epithelial carcinoma cells, and doxorubicin treated human small cell lung cancer cells. ${ }^{40}$ Chemotherapy-induced IL8 signalling promotes resistance in cancer cells via upregulation of 
prosurvival protein such as cellular FLICE-inhibitory protein (cFLIP). ${ }^{31}$ Abrogation of TG-induced IL-8 expression and increased apoptosis in presence of Api suggests that, the combination of these two drugs may overcome IL-8-mediated cell survival and resistance. Apoptosis is an outcome of a diverse cascade of cellular events mediated by several molecules including caspases and proapoptotic proteins. ${ }^{41,42}$ The combination of TG and Api promotes caspase-8, caspase-9, and Bax mediated apoptosis. Cytokinemediated Bax deficiency and consequent delayed apoptosis has already been reported in neutrophils. ${ }^{43}$ Our findings provide evidence that Bax downregulates IL-8 expression in colon and prostate cancer cells.

The anti-apoptotic mechanism of mitochondrial chaperone Hsp60 involves sequestration of Bax-containing complexes that may lead to the inhibition of apoptotic cell death. ${ }^{22}$ We observed a new role of $\mathrm{Hsp60}$ in regulating IL-8 and cell survival in colon and prostate cancer. Api and TG combination disrupts Hsp60-IL-8 axis, and therefore, may overcome apoptosis resistance. Similar to our study, knockdown of $I L-8$ has also been reported to increase sensitivity to cisplatin in platinumsensitive cells and reversed platinum resistance in resistant cell lines. ${ }^{44}$ We demonstrated regulation of IL-8 production and release by $\mathrm{Hsp} 60$ in vitro and in vivo. To validate IL- 8 release by tumour cells, we used immune deficient SCID mice to study regulation of IL-8 by Hsp60. Since we used PC-3 human prostate cancer cells for xenograft studies and determined IL-8 production by using anti-human IL-8 antibody, our results confirmed production and release of IL- 8 by cancer cells (and not from murine cells) and its regulation by Hsp60. Increased IL-8 in serum associates with poor response to cancer therapeutics. ${ }^{45}$ IL-8 recruits pro-tumorigenic factors to remodel TME. ${ }^{46}$ IL-8 expression in cancer-associated fibroblasts (CAFs) also modulates TME leading increased NF-KB activation and chemoresistance in human gastric cancer. ${ }^{47}$ Thus, downregulation of IL-8 release in serum and decreased expression in tumour sections upon Hsp60 knockdown PC-3 xenograft suggest that Hsp60 promotes tumour progression via IL-8-mediated TME remodelling. TGF- $\beta$ signalling regulates IL- 8 expression in cancer cells including human prostate cancer cells. ${ }^{14}$ Although regulation of IL-8 is contributed by TGF- $\beta$, exposure of Hsp60 causes elevated TGF- $\beta$ expression in diseased conditions. ${ }^{48,49}$ Api-induced TGF- $\beta$ was diminished by TG, suggesting that the combined exposure of Api and TG may overcome apoptotic resistance mediated by the IL-8-TGF- $\beta$ axis. Interestingly, Hsp60 regulates both IL- 8 and TGF- $\beta$ pro-survival interleukins and acts as an upstream regulator of IL-8-TGF- $\beta$ signalling axis.

In summary, we report that Hsp60 regulates IL-8 and TGF- $\beta$ production and their release in cancer cells. Hsp60-mediated upregulation of IL- 8 and TGF- $\beta$ correlates with downregulation of caspase activities and inhibition of apoptotic cell death. Combined exposure of Api and TG may abrogate Hsp60-IL-8-TGF- $\beta$ axis to overcome apoptotic resistance in cancer cells. IL-8 is an autocrine growth factor remodels TME and associates with disease recurrence in many types of cancer including in prostate and colon cancer. ${ }^{13,50,51}$ Increased expression of Hsp60 contributes tumour progression, apoptosis inhibition, modulation of TME, therapy resistance, and recurrence of many types of cancer. ${ }^{19,52-58}$ This study provides strong evidence of Hsp60 regulation of IL-8 expression and release, which plays critical role TME remodelling and therapeutic resistance in cancer. Therefore, targeting Hsp60IL-8 axis could have a potential therapeutic outcome in colorectal and prostate malignancies.

\section{AUTHOR CONTRIBUTIONS}

S.K., N.Y. and D.C. conceptualised the study; S.K. and D.C. designed the experiments; S.K., A.K.C. and N.Y. performed the experiments; S.K., J.O., R.K., J.R.I., N.Y. and D.C. analysed the data; S.K. and D.C. wrote the paper.

\section{ADDITIONAL INFORMATION}

Competing interests: The authors declare no competing interests.

Ethics approval and consent to participate: All experiments were performed in accordance with relevant guidelines and regulations. Animal experiments were approved by and performed in compliance with the guidelines and regulations by Institutional Animal Care and Use Committee (IACUC, protocol \# 1306M) of the Roswell Park Comprehensive Cancer Center. 6-8-weeks-old SCID male mice were purchased from the Roswell Park Division of Laboratory Animal Resources (DLAR). Primary tumours and normal tissues from patients were collected at Roswell Park Comprehensive Cancer Center (Roswell Park) by the Pathology Network Shared Resource (PNSR). Appropriate Institutional Review Board approval consistent with federal, state and local requirements was obtained (including informed consent from the subjects) for this study. The patient's samples were de-identified by PNSR and patient information was not provided to researchers.

Funding: This work was supported by the National Cancer Institute of the National Institutes of Health under Award Number RO1-CA160685 and the American Cancer Society Research Scholar Grant RSG-12-214-01- CCG to DC, and in part by the National Cancer Institute Center Support Grant P30-CA016056 to the Roswell Park Comprehensive Cancer Center that supports the Pathology Network, Flow and Image Cytometry, Genomics, Bioinformatics, Biostatistics, Immune Analysis Shared Resources and the Onsite Supply Center.

Consent to publish: All authors provide consent for publication.

Data availability: Summarised primary research data are presented in the paper. No publicly available dataset has been generated as part of this work.

Note: This work is published under the standard license to publish agreement. After 12 months the work will become freely available and the license terms will switch to a Creative Commons Attribution 4.0 International (CC BY 4.0).

Publisher's note Springer Nature remains neutral with regard to jurisdictional claims in published maps and institutional affiliations.

\section{REFERENCES}

1. Lippitz, B. E. Cytokine patterns in patients with cancer: a systematic review. Lancet Oncol. 14, e218-e228 (2013).

2. Li, A., Dubey, S., Varney, M. L., Dave, B. J. \& Singh, R. K. IL-8 directly enhanced endothelial cell survival, proliferation, and matrix metalloproteinases production and regulated angiogenesis. J. Immunol. 170, 3369-3376 (2003).

3. Heidemann, J., Ogawa, H., Dwinell, M. B., Rafiee, P., Maaser, C., Gockel, H. R. et al. Angiogenic effects of interleukin 8 (CXCL8) in human intestinal microvascular endothelial cells are mediated by CXCR2. J. Biol. Chem. 278, 8508-8515 (2003).

4. Yuan, A., Yang, P. C., Yu, C. J., Chen, W. J., Lin, F. Y., Kuo, S. H. et al. Interleukin-8 messenger ribonucleic acid expression correlates with tumour progression, tumour angiogenesis, patient survival, and timing of relapse in non-small-cell lung cancer. Am. J. Respir. Crit. Care Med. 162, 1957-1963 (2000).

5. Xia, W., Chen, W., Zhang, Z., Wu, D., Wu, P., Chen, Z. et al. Prognostic value, clinicopathologic features and diagnostic accuracy of interleukin-8 in colorectal cancer: a meta-analysis. PloS one. 10, e0123484 (2015).

6. Xiao, Y. C., Yang, Z. B., Cheng, X. S., Fang, X. B., Shen, T., Xia, C. F. et al. CXCL8, overexpressed in colorectal cancer, enhances the resistance of colorectal cancer cells to anoikis. Cancer Lett. 361, 22-32 (2015).

7. Ning, Y., Manegold, P. C., Hong, Y. K., Zhang, W., Pohl, A., Lurje, G. et al. Interleukin-8 is associated with proliferation, migration, angiogenesis and chemosensitivity in vitro and in vivo in colon cancer cell line models. Int. J. Cancer. 128, 2038-2049 (2011).

8. Wakabayashi, Y., Shono, T., Isono, M., Hori, S., Matsushima, K., Ono, M. et al. Dual pathways of tubular morphogenesis of vascular endothelial cells by human glioma cells: vascular endothelial growth factor/basic fibroblast growth factor and interleukin-8. Jpn. J. Cancer Res. 86, 1189-1197 (1995).

9. Kido, S., Kitadai, Y., Hattori, N., Haruma, K., Kido, T., Ohta, M. et al. Interleukin 8 and vascular endothelial growth factor-prognostic factors in human gastric carcinomas? Eur. J. Cancer. 37, 1482-1487 (2001).

10. Kitadai, Y., Haruma, K., Sumii, K., Yamamoto, S., Ue, T., Yokozaki, H. et al. Expression of interleukin-8 correlates with vascularity in human gastric carcinomas. Am. J. Pathol. 152, 93-100 (1998).

11. Li, A., Varney, M. L. \& Singh, R. K. Expression of interleukin 8 and its receptors in human colon carcinoma cells with different metastatic potentials. Clin. Cancer Res. 7, 3298-3304 (2001). 
12. Haraguchi, M., Komuta, K., Akashi, A., Matsuzaki, S., Furui, J. \& Kanematsu, T. Elevated IL-8 levels in the drainage vein of resectable Dukes' C colorectal cancer indicate high risk for developing hepatic metastasis. Oncol. Rep. 9, 159-165 (2002).

13. Araki, S., Omori, Y., Lyn, D., Singh, R. K., Meinbach, D. M., Sandman, Y. et al. Interleukin-8 is a molecular determinant of androgen independence and progression in prostate cancer. Cancer Res. 67, 6854-6862 (2007).

14. Lu, S. \& Dong, Z. Characterization of TGF-beta-regulated interleukin-8 expression in human prostate cancer cells. Prostate. 66, 996-1004 (2006).

15. Caruso Bavisotto, C., Cappello, F., Macario, A. J. L., Conway de Macario, E., Logozzi, M., Fais, S. et al. Exosomal HSP60: a potentially useful biomarker for diagnosis, assessing prognosis, and monitoring response to treatment. Expert Rev. Mol. Diagn. 17, 815-822 (2017).

16. Lee, Y. S., Choi, I., Ning, Y., Kim, N. Y., Khatchadourian, V., Yang, D. et al. Interleukin-8 and its receptor CXCR2 in the tumour microenvironment promote colon cancer growth, progression and metastasis. Br. J. Cancer. 106, 1833-1841 (2012).

17. Cappello, F., David, S., Rappa, F., Bucchieri, F., Marasa, L., Bartolotta, T. E. et al. The expression of HSP60 and HSP10 in large bowel carcinomas with lymph node metastase. BMC Cancer. 5, 139 (2005)

18. Castilla, C., Congregado, B., Conde, J. M., Medina, R., Torrubia, F. J., Japon, M. A. et al. Immunohistochemical expression of Hsp60 correlates with tumour progression and hormone resistance in prostate cancer. Urology. 76, 1017 e1-6 (2010).

19. Glaessgen, A., Jonmarker, S., Lindberg, A., Nilsson, B., Lewensohn, R., Ekman, P. et al. Heat shock proteins 27,60 and 70 as prognostic markers of prostate cancer. APMIS. 116, 888-895 (2008).

20. Mori, D., Nakafusa, Y., Miyazaki, K. \& Tokunaga, O. Differential expression of Janus kinase 3 (JAK3), matrix metalloproteinase 13 (MMP13), heat shock protein 60 (HSP60), and mouse double minute 2 (MDM2) in human colorectal cancer progression using human cancer cDNA microarrays. Pathol. Res. Pract. 201, 777-789 (2005).

21. Franco, L., Terrinca, J., Rodriguez, A. B., Espino, J. \& Pariente, J. A. Extracellular heat shock proteins protect $\mathrm{U} 937$ cells from H2O2-induced apoptotic cell death. Mol. Cell Biochem. 412, 19-26 (2016).

22. Ghosh, J. C., Dohi, T., Kang, B. H. \& Altieri, D. C. Hsp60 regulation of tumour cell apoptosis. J. Biol. Chem. 283, 5188-5194 (2008).

23. Zhang, L., Yu, J., Park, B. H., Kinzler, K. W. \& Vogelstein, B. Role of BAX in the apoptotic response to anticancer agents. Science. 290, 989-992 (2000).

24. von Haefen, C., Wieder, T., Gillissen, B., Starck, L., Graupner, V., Dorken, B. et al. Ceramide induces mitochondrial activation and apoptosis via a Bax-dependent pathway in human carcinoma cells. Oncogene. 21, 4009-4019 (2002).

25. Chandra, D., Liu, J. W. \& Tang, D. G. Early mitochondrial activation and cytochrome c up-regulation during apoptosis. J. Biol. Chem. 277, 50842-50854 (2002).

26. Chandra, D., Choy, G., Deng, X., Bhatia, B., Daniel, P. \& Tang, D. G. Association of active caspase 8 with the mitochondrial membrane during apoptosis: potential roles in cleaving BAP31 and caspase 3 and mediating mitochondrionendoplasmic reticulum cross talk in etoposide-induced cell death. Mol. Cell Biol. 24, 6592-6607 (2004).

27. Liu, Q., Li, A., Tian, Y., Wu, J. D., Liu, Y., Li, T. et al. The CXCL8-CXCR1/2 pathways in cancer. Cytokine Growth Factor Rev. 31, 61-71 (2016).

28. Alfaro, C., Sanmamed, M. F., Rodriguez-Ruiz, M. E., Teijeira, A., Onate, C., Gonzalez, A. et al. Interleukin-8 in cancer pathogenesis, treatment and follow-up. Cancer Treat.Rev. 60, 24-31 (2017)

29. Kim, Y. K., Lee, E. K., Kang, J. K., Kim, J. A., You, J. S., Park, J. H. et al. Activation of NF-kappaB by HDAC inhibitor apicidin through Sp1-dependent de novo protein synthesis: its implication for resistance to apoptosis. Cell Death Differ 13, 2033-2041 (2006).

30. Yu, Y., De Waele, C. \& Chadee, K. Calcium-dependent interleukin-8 gene expression in T84 human colonic epithelial cells. Inflammation Res. 50, 220-226 (2001).

31. Wilson, C., Wilson, T., Johnston, P. G., Longley, D. B. \& Waugh, D. J. Interleukin-8 signalling attenuates TRAIL- and chemotherapy-induced apoptosis through transcriptional regulation of c-FLIP in prostate cancer cells. Mol. Cancer Ther. 7 2649-2661 (2008).

32. Han, J. W., Ahn, S. H., Park, S. H., Wang, S. Y., Bae, G. U., Seo, D. W. et al. Apicidin, a histone deacetylase inhibitor, inhibits proliferation of tumour cells via induction of p21WAF1/Cip1 and gelsolin. Cancer Res. 60, 6068-6074 (2000).

33. Yamaguchi, H., Bhalla, K. \& Wang, H. G. Bax plays a pivotal role in thapsigargininduced apoptosis of human colon cancer HCT116 cells by controlling Smac/ Diablo and Omi/HtrA2 release from mitochondria. Cancer Res. 63, 1483-1489 (2003).

34. Futami, T., Miyagishi, M. \& Taira, K. Identification of a network involved in thapsigargin-induced apoptosis using a library of small interfering RNA expression vectors. J. Biol. Chem. 280, 826-831 (2005).
35. Chandra, D., Bratton, S. B., Person, M. D., Tian, Y., Martin, A. G., Ayres, M. et al. Intracellular nucleotides act as critical prosurvival factors by binding to cytochrome C and inhibiting apoptosome. Cell. 125, 1333-1346 (2006).

36. Mcllwain, D. R., Berger, T., Mak, T. W. Caspase functions in cell death and disease Cold Spring Harb Perspect Biol. 5:a008656 (2013).

37. Tait, S. W. \& Green, D. R. Mitochondria and cell death: outer membrane permeabilization and beyond. Nat. Rev. Mol. Cell Biol. 11, 621-632 (2010).

38. Shan, Y. X., Liu, T. J., Su, H. F., Samsamshariat, A., Mestril, R. \& Wang, P. H. Hsp10 and $\mathrm{Hsp} 60$ modulate $\mathrm{Bcl}-2$ family and mitochondria apoptosis signalling induced by doxorubicin in cardiac muscle cells. J. Mol. Cell Cardiol. 35, 1135-1143 (2003).

39. Jones, V. S., Huang, R. Y., Chen, L. P., Chen, Z. S., Fu, L. \& Huang, R. P. Cytokines in cancer drug resistance: Cues to new therapeutic strategies. Biochim. Biophys. Acta. 1865, 255-265 (2016).

40. Levina, V., Su, Y., Nolen, B., Liu, X., Gordin, Y., Lee, M. et al. Chemotherapeutic drugs and human tumour cells cytokine network. Int. J. Cancer. 123, 2031-2040 (2008).

41. Lopez, J. \& Tait, S. W. Mitochondrial apoptosis: killing cancer using the enemy within. Br. J. Cancer. 112, 957-962 (2015).

42. Yadav, N. \& Chandra, D. Mitochondrial and postmitochondrial survival signalling in cancer. Mitochondrion. 16, 18-25 (2014).

43. Dibbert, B., Weber, M., Nikolaizik, W. H., Vogt, P., Schoni, M. H., Blaser, K. et al. Cytokine-mediated Bax deficiency and consequent delayed neutrophil apoptosis: a general mechanism to accumulate effector cells in inflammation. Proc. Natl Acad. Sci. USA 96, 13330-13335 (1999).

44. Stronach, E. A., Cunnea, P., Turner, C., Guney, T., Aiyappa, R., Jeyapalan, S. et al. The role of interleukin-8 (IL-8) and IL-8 receptors in platinum response in high grade serous ovarian carcinoma. Oncotarget. 6, 31593-31603 (2015).

45. Bussard, K. M., Mutkus, L., Stumpf, K., Gomez-Manzano, C. \& Marini, F. C. Tumourassociated stromal cells as key contributors to the tumour microenvironment. $\mathrm{Br}$. Cancer Res. 18, 84 (2016).

46. Palena, C., Hamilton, D. H. \& Fernando, R. I. Influence of IL-8 on the epithelialmesenchymal transition and the tumour microenvironment. Future Oncol. 8, 713-722 (2012).

47. Zhai, J., Shen, J., Xie, G., Wu, J., He, M., Gao, L. et al. Cancer-associated fibroblastsderived IL-8 mediates resistance to cisplatin in human gastric cancer. Cancer Lett. 454, 37-43 (2019).

48. Shiny, C., Krushna, N. S., Babu, S., Elango, S., Manokaran, G. \& Narayanan, R. B. Recombinant Wolbachia heat shock protein 60 (HSP60) mediated immune responses in patients with lymphatic filariasis. Microbes Infect. 13, 1221-1231 (2011).

49. Li, H., Ding, Y., Yi, G., Zeng, Q. \& Yang, W. Establishment of nasal tolerance to heat shock protein-60 alleviates atherosclerosis by inducing TGF-beta-dependent regulatory T cells. J. Huazhong Univ Sci Technolog Med Sci. 32, 24-30 (2012).

50. Caruso, D. J., Carmack, A. J., Lokeshwar, V. B., Duncan, R. C., Soloway, M. S. \& Lokeshwar, B. L. Osteopontin and interleukin-8 expression is independently associated with prostate cancer recurrence. Clin. Cancer Res. 14, 4111-4118 (2008).

51. Lurje, G., Zhang, W., Schultheis, A. M., Yang, D., Groshen, S., Hendifar, A. E. et al. Polymorphisms in VEGF and IL-8 predict tumour recurrence in stage III colon cancer. Ann. Oncol. 19, 1734-1741 (2008).

52. Chaudhary, A. K., Bhat, T. A., Kumar, S., Kumar, A., Kumar, R., Underwood, W. et al. Mitochondrial dysfunction-mediated apoptosis resistance associates with defective heat shock protein response in African-American men with prostate cancer. Br. J. Cancer. 114, 1090-1100 (2016).

53. Ghosh, J. C., Siegelin, M. D., Dohi, T. \& Altieri, D. C. Heat shock protein 60 reg ulation of the mitochondrial permeability transition pore in tumour cells. Cancer Res. 70, 8988-8993 (2010).

54. Chandra, D., Choy, G. \& Tang, D. G. Cytosolic accumulation of HSP60 during apoptosis with or without apparent mitochondrial release: evidence that its proapoptotic or pro-survival functions involve differential interactions with caspase3. J. Biol. Chem. 282, 31289-31301 (2007).

55. Cornford, P. A., Dodson, A. R., Parsons, K. F., Desmond, A. D., Woolfenden, A Fordham, M. et al. Heat shock protein expression independently predicts clinical outcome in prostate cancer. Cancer Res. 60, 7099-7105 (2000).

56. Rappa, F., Pitruzzella, A., Marino Gammazza, A., Barone, R., Mocciaro, E., Tomasello, G. et al. Quantitative patterns of Hsps in tubular adenoma compared with normal and tumour tissues reveal the value of Hsp10 and Hsp60 in early diagnosis of large bowel cancer. Cell Stress Chaperones 21, 927-933 (2016).

57. Hamelin, C., Cornut, E., Poirier, F., Pons, S., Beaulieu, C., Charrier, J. P. et al. Identification and verification of heat shock protein 60 as a potential serum marker for colorectal cancer. The FEBS J. 278, 4845-4859 (2011).

58. Campanella, C., Rappa, F., Sciume, C., Marino Gammazza, A., Barone, R., Bucchieri, F. et al. Heat shock protein 60 levels in tissue and circulating exosomes in human large bowel cancer before and after ablative surgery. Cancer. 121, 3230-3239 (2015). 